\title{
Retraction Note to: The model for improving big data sub-image retrieval performance using scalable vocabulary tree based on predictive clustering
}

\author{
Quan-Dong Feng $^{1} \cdot$ Miao Xu ${ }^{1} \cdot$ Xin Zhang ${ }^{2}$
}

Published online: 20 October 2017

(C) Springer Science+Business Media, LLC 2017

\section{Retraction Note to: Cluster Comput (2016) 19:699-708 \\ DOI 10.1007/s10586-016-0551-3}

Following detailed consultation with the Editor-in-Chief of the Journal and the corresponding author, The Publisher has retracted this article, due to significant, unauthorized use of content from a paper titled, "Improving Bag-ofVisual-Words Image Retrieval with Predictive Clustering Trees", authored by Dimitrovski et al, published in Elsevier's journal on Information Sciences.

The online version of the original article can be found under doi: 10 . 1007/s10586-016-0551-3.

\footnotetext{
Quan-Dong Feng fqdlsec@yeah.net

1 College of Science, Beijing Forestry University, Beijing 100083, China

2 School of Electrical Engineering and Automation, Tianjin Polytechnic University, Tianjin 300387, China
} 